\title{
The Role of E-Learning in the Professional Development of Student Teachers in Cameroon: A Discourse in Curriculum
}

\author{
Mutendwahothe Walter Lumadi \\ Kibinkiri Eric Len \\ Department of Curriculum and Instruction, College of Education, \\ University of South Africa, South Africa \\ E-mail: lumadmw@unisa.ac.za, kibinkirieric@yahoo.com
}

Doi:10.5901/mjss.2013.v4n13p791

\begin{abstract}
This study was planned to investigate "the role of e-learning in the professional development of student teachers in Cameroon". Nevertheless, the ineffectiveness of traditional or conventional methods of teaching and learning in education motivated the researchers to carry out this study. In order to proceed, six hypotheses were formulated to guide the investigation A survey of 796 student-teachers drawn from eight primary government teacher training colleges and three higher teacher training colleges in Cameroon was carried out. Data were collected using a questionnaire that was carefully designed with respect to the variables under study. Results revealed that the use of e-learning has a significant influence on the professional development of student teachers in Cameroon. Findings further revealed that internet-based problem-solving and computer-based direct instruction are the best predictors of the professional development of student teachers in Cameroon. Consequently, recommendations are made to teacher training institutions to adopt alternative and multidimensional perspectives (models) in their training programmes in order to solve existing and future educational challenges.
\end{abstract}

\section{Introduction}

The Cameroon educational system has witnessed consistent evolution in its policies, strategies, methods, pedagogical resources and practices marked by its political evolution and exigencies. However, to effectively study the ideas and developments that have shaped educational practices in order to conceptualise initial professional training in Cameroon's schools, it is imperative to briefly examine its history. Education in Cameroon has a long history. Indigenous African societies including Cameroon had their own system of educating and training younger ones which included the use of pedagogical resources before the introduction of a western type of education. The type of training received by Africans was called indigenous education, because it was part and parcel of the society. These African practices were not printed or recorded in books. Thus, the West referred to that kind of education as "primitive education" because it lacked backup documentation.

However, indigenous or African education was a process which enabled society to teach its younger ones the life patterns of the society so that they could live successfully within the context of their culture. The main objective of this kind of education was to train and integrate children into the working population. Fonkeng (2007:32) points out that African education consisted of activities aimed at developing children's motor or physical skills used for construction, farming, pottery, weaving, hunting, and carving; character and moral training; intellectual skills; vocational development and the development of a sense of belonging and cultural heritage. He, furthermore, argues that "traditional African education addressed issues of modern education particularly, with reference to the transmission of the cultural heritage in view of continuity and growth for the regulation of life in the society" (Fonkeng, 2007:32). Falola (2000:50) highlights that the learning process was a cultural activity and collective affair involving the task of socialising.

More still, the education process involved the use of rudimentary tools, life-long learning, oral learning, storytelling, collaborative learning, community-based, informal processes. It responded to societal needs since it focused on providing knowledge, skills and attitudes for immediate consumption. Unfortunately, reforms in education over the years seemed to overlook their historical base just as colonial education policies ignored and downgraded African cultural knowledge and practices that influenced indigenous education (Tambo, 2000:152). According to Tamanji (2011:320) the collaboration between the colonial governments and the western Christian missionaries resulted in the establishment of colonial formal schools in Cameroon. Consequently, Formal education in Cameroon is closely linked to the West through 
trade, Evangelisation and colonisation. The problems involved in this kind of education are becoming more complex. Some of these problems include insufficiently qualified staff, an insufficient infrastructure and ineffective teaching and learning strategies. The direct result is always poor outcomes to educational investments. Consequently, strategies to attend to these problems must be viewed in a multidimensional or multifaceted manner with respect to the context and the availability of means. However, the professional development of student teachers must be the first priority for the country to solve its existing and future educational problems. This is the key to education for sustainable development.

Furthermore, the incorporation of information and communication technologies (ICTs) into educational practices promises more benefits to education and has the potential to change the existing paradigmsThese tools have influenced the development of new models, strategies and methods of teaching and learning in education. Crook (2004:19) affirms that the emergence of new educational technologies has catalysed fresh discussions of educational theory and practice. As a matter of fact, current educational developments all over the world are being driven by ICTs. These technologies have changed the way in which people think and behave in society. Worthy of note is the fact that pupils and students in Cameroon, like in other developing countries, have a strong passion to own and use ICT gadgets as their prices and services offered decrease on a daily basis.

Despite increased understanding of ICTs in governance, business and in the development process, there is still much to be learned about the concept and practice of e-learning in education especially in teacher education. ICTs have increased students' interest in learning, but have not changed the basic structure of the teaching-learning process - the daily activities in the average classroom. For example, the whole-class, time-based lecturing method still dominates in most classrooms. E-learning has the potential to change education in Cameroon. As a matter of fact, it has the capacity to offer student teachers and teachers numerous opportunities to develop their talents so that they can contribute to the development of their communities.

\section{Literature Review}

\subsection{Conceptual Framework}

E-learning is multidimensional and dynamic, and changes according to context, circumstances and interests. As a matter of fact, it is difficult to define the term "e-learning". Perkinson (2005:104) defines e-learning as "instructional content or learning experiences delivered or enabled by electronic technology". According to Commonwealth of Learning (2006), elearning and online learning are terms that have emerged to describe the application of ICTs to enhance distance education, implement open-learning policies, make learning activities more flexible and enable such learning activities to be distributed among many learning venues. On his part Naidu (2003:8) defines e-learning as "the systematic use of networked information and communication technology in teaching and learning". Thus e-learning is an all-encompassing term which includes computer-enhanced learning, the use of mobile technologies such as Personal Digital Assistants (PDAs) and MP3 players to facilitate learning.

As far as this work is concerned, e-learning is a modern strategy or method of teaching and learning which involves Computer-Based Direct Instruction (CBDI) - direct instructions for example, lectures, demonstrations and illustrations facilitated or enhanced by ICTs; Asynchronous Experiential Learning (AEL) - experiential learning enhanced by the internet and its facilities; Asynchronous Collaborative Learning $(\mathrm{ACL})$ - cooperative or interactive strategy (discussion method) enhanced or facilitated by the internet and its facilities;. Internet Based Problem Solving (IBPS) - a problem-solving method improved by the internet and its facilities; Online Content Representation; (OCR) - the diverse representation and presentation of information on the internet (text, audio, video, audio visual, graphic, picture format) and Online Learning Environments (OLE) - the flexibility, limitless storage, user-friendly, accessibility features or characteristics of an online platform. Electronic applications and processes involved include the internet, handheld devices (personal digital assistance, simple mobile phones, smart phones, and tablets), television and digital radio. .

\subsection{Theoretical Framework}

The main theories that underpinned this study will be discussed in this section, among which are socio-constructivism and cultural theories. These theories will be discussed in light of their relevance to ICTs and e-learning. Crook (2001:21) points out that constructivism, specifically socio-constructivism, confronted behaviourism and cognitivism which makes it more appealing. Constructivism became influential in education through the works of Piaget and Vygotsky. Santrock (2004:51) assert that, like Piaget, Vygotsky (1896-1934) "believed that children actively construct their knowledge". He 
introduced zone of proximal (or potential) development (ZPD) in education. ZPD is the difference between what a child can understand on his or her own and what he or she can potentially understand through interaction with others or learning support. Vygotsky suggests that teaching and learning are "social activities that take place between social actors in socially constructed situations" (Moore, 2000:15). According to Tu (2000:33), Vygotsky's theory, "full cognitive development requires social interaction". Children construct knowledge through social interaction with others. E-learning has the capacity to help children create their own knowledge through social interaction. This implies that educators must learn to create many opportunities for students to learn with the teacher and more skilled peers. It is worthy to note that Lev Vygotsky's views of learning have influenced the growth of many approaches and theories in education, for example, the cultural approach to instruction.

The cultural approach has challenged the concerns of behaviourism, cognitivism and constructivism which make it more comprehensive in its scope. Crook (2001:19) points out that the cultural view frames intelligent action as something that is mediated. According to him, the vision of behaviourism is evident in the design of early teaching machines which focused on computer-assisted instruction (Crook, 2001:22). A favourable environment or good conditions for learning to the cultural approach is one in which the learner is granted access to complete versions of what is to be acquired rather than starting at a distance and incrementally moving forward as is the case with behaviourism. In this approach the learner is an active participant in the learning process. Conditions are created for learner participation. On his part, Brown (2002:53) presumes that learners often construct and augment their own understanding of the content socially through conversations. Worthy of note is the fact that the cultural approach conceptualises learning and knowledge as participatory, distributed and socially situated. The aim of supporting a learner is to capture the integrity of the complete system to be learned, rather than reducing it to components for bottom-up acquisition.

Moreover, the cultural approach has led to deeper reflection on the incorporation of modern ICTs into education. The development of notions such as systems thinking, problem-solving, activity-centred design to instruction and activity theory stemmed from such thinking. Jonassen (2003:364) holds that problem representation is the key to problemsolving. Commonwealth of Learning (2000:8) highlights that a systems approach sets the conditions for proceeding in an orderly way when designing instructions or programmes, for example, open and distance learning. It holds the view that the whole as well as the different interrelated components that make up the system are all important. Gifford and Enyedy (1999:189) state that activity centred design (ACD) is a model or design for computer-supported collaborative learning environments based on the assumptions that: activity is mediated by cultural tools and must be conceptualised on a number of interdependent levels and that conceptual understanding is first established socially. In this light, Gifford and Enyedy (1999:189) view learning as a complex process in which an individual's cognition is defined by its relation to the material setting and the forms of social participation encouraged by these settings.

Furthermore, Cole and Engestrom (1991) in Bottino et al (1999:283) design a model that shows the complex relationships between elements in an activity. According to their systemic model there are three important mutual relationships involved in every activity. This includes the relationship between subject and object, subject and community and object and community. Each of these relationships is mediated by a third unit. The relationship between the subject and the object of the activity is mediated by tools. That between subject and community is mediated by rules (explicit or implicit norms, conventions, social interactions), while that between object and community is mediated by division of labour (different roles characterising the system which is important for transforming the object into an outcome). In activity, theory activities are influenced by other activities. External factors can change some elements of activities causing contradictions (problems, ruptures, breakdowns). In this theory contradictions are considered as a basis of development.

Fig. 1: Cole and Engestrom's Model of Activity (1991) adopted from Bottino et al (1999:283)

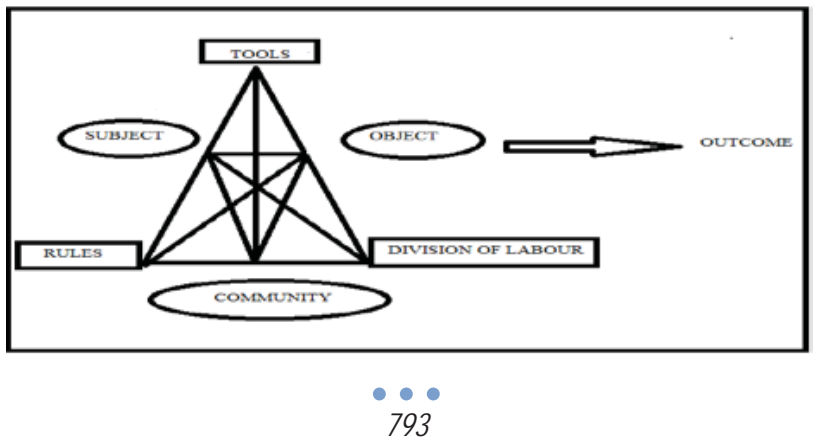


Nevertheless, it is interesting to note that Paulo Freire's thinking is in line with activity theory. Freire (1984:12) championed a "critical pedagogy" which views people as subjects, not objects, who are constantly reflecting and acting on the transformation of their world so that it can become a more equitable place for all to live in. In Freire's pedagogy, he denounces teacher-centred classrooms and illustrates how education could transform society by helping the oppressed to develop critical consciousness

Finally, this study is designed to determine "the role of e-learning in the professional development of student teachers". More specifically, the role of e-learning in prospective teachers' communication skills, technical skills suitable for learning, interactivity/interpersonal skills, attitudes towards learning with technology, support received by ICT teachers, values and principles suitable for learning in the 21st century, performance in educational technology, and the challenges faced by teachers in the implementation of e-learning. In order to proceed, the following research hypotheses were formulated to guide the study: General research hypotheses

The utilisation of e-learning has a significant influence on the professional development of student teachers in Cameroon.

\subsection{Specific Research Hypotheses}

\subsubsection{Hypotheses 1}

Alternative Hypotheses ( $\mathrm{Ha}$ ):computer-based direct instruction has a significant influence on the professional development of student teachers.

\subsubsection{Hypotheses 2}

Alternative Hypotheses (Ha): asynchronous experiential learning has a significant influence on the professional development of student teachers.

\subsubsection{Hypotheses 3}

Alternative Hypotheses ( $\mathrm{Ha}$ ): asynchronous collaborative learning has a significant influence on the professional development of student teachers.

\subsubsection{Hypotheses 4}

Alternative Hypotheses (Ha): internet-based problem-solving has a significant influence on the professional development of student teachers.

\subsubsection{Hypotheses 5}

Alternative Hypotheses ( $\mathrm{Ha}$ ): online content representation has a significant influence on the professional development of student teachers.

\subsubsection{Hypotheses 6}

Alternative Hypotheses ( $\mathrm{Ha}$ ): online learning environment has a significant influence on the professional development of student teachers.

\section{Research Methodology}

This study was carried out in Cameroon specifically in government teacher training colleges. The country is subdivided into ten regions (North West, South West, West, Littoral, Centre, South, East, Adamawa, North and Far North). Each region is further subdivided into divisions and subdivisions. The regions are administered by appointing regional delegates of education in addition to divisional and subdivisional delegates. The respective ministers of education coordinate and implement government policies on education in the country at national level. The economy is basically 
agricultural and commonly described as Africa in miniature or the basket of West Africa. Concerning teacher education, the country has 59 primary government teacher training colleges that train teachers of basic general education. As far as higher education is concerned, the country has eight state universities five of which have higher teacher training colleges that train teachers of secondary education in both technical and general education. These include the Higher Teacher Training College Yaounde of the University of Yaounde I, The Higher Teacher Training College and the Higher Technical Teacher Training College Bamenda of the University of Bamenda, The Higher Teacher Training College Maroua of the University of Maroua, the Higher Technical Teacher Training college Douala of the University of Douala and the Faculty of Education of the University of Buea. Cameroon has two official languages, namely English and French.

Moreover, the target population was made up of third year (final year) student teachers. Purposive sampling, cluster sampling, simple random sampling and systematic random sampling techniques were applied where necessary to obtain the sample. Consequently, a survey of 796 student teachers drawn from eight primary government teacher training colleges and three higher teacher training colleges in Cameroon was carried out. Data were collected using a questionnaire that was carefully designed with respect to the variables under study. The student t-test, one-way ANOVA and correlation coefficient were used to test the research hypotheses.

\section{Findings and Discussions}

The first research hypothesis (RH1) asserts that computer-based direct instruction (CBDI) has a significant influence on the professional development of student teachers. The results of the correlation between CBDI and the professional development of student teachers show the following: $r(794)=0.231,(p<0.001)$. From this finding, inference was made that CBDI has a significant influence on the professional development of student teachers. The magnitude of the effect was verified by the test value which gave a coefficient of determination of 0.0533 ; which means that $5.33 \%$ of the variability of the professional development of student teachers could be explained by CBDI. Furthermore, when the responses of the student teachers on the questionnaire in relation to CBDI were scored and categorised, it was observed that all the items (presentation of course outline; rules and procedures online; enhancement of face-to-face tutoring and competence-based teaching; demonstration and illustration to a large group online) categorised under CBDI were very important to the respondents considering the slight differences in the means and standard deviations. This finding is substantial as competence-based teaching is the main approach that is used in all the primary and secondary schools in Cameroon. This result is in line with the views of behaviourism as a theory of learning. It is worthy to note that behaviourism, although old, still has a place in education. The behaviourists view learning as an induction of a required behaviour (Bottino, 2004:555). The focus of this kind of pedagogy is to make the transmission of knowledge more efficient. According to Crook (2001:32), multimedia can help lecturers package their lecture notes as web pages for students to consult anywhere at all times.. He further explains that a lecture in this format has at least two social dimensions - first, the corporate nature of the lecture (participation) makes it a social occasion; and second, the personalised nature of the disciplinary exploration which also makes it a social occasion.

The second research hypothesis (RH2) asserts that asynchronous experiential learning (AEL) has a significant influence on the professional development of student teachers. The findings of the correlation between AEL and the professional development of student teachers show the following: $r(794)=0.070,(p<0.05)$. From the finding, inference made was that $A E L$ has a significant influence on the professional development of student teachers. The test value gave a coefficient of determination of 0.0049 which means that $0.49 \%$ of the variability of the professional development of student teachers is explained by AEL. Moreover, when the responses of the student teachers on the questionnaire in relation to AEL were scored and categorised, it was observed that all the items (enhancement of observation; integration of theory and practice; strengthening of investigation; self-directed learning; transfer of learning and generalisation in an online platform) categorised under AEL were very important to the respondents considering the slight differences in the means and standard deviations. Long (2004:17) argues that this mode of e-learning is characterised by its nature of learner-facilitator interaction where the contribution of the facilitator is temporally static. According to him, information is presented in recorded format and the learner can interact with it any time thereafter

The third research hypothesis $(\mathrm{RH} 3)$ claims that asynchronous collaborative learning ( $\mathrm{ACL}$ ) has a significant influence on the professional development of student teachers. The results of the correlation between $A C L$ and the professional development of student teachers show the following: $r(794)=0.117,(p<0.001)$. From this result, a conclusion was made that $\mathrm{ACL}$ has a significant influence on the professional development of student teachers. The test value gave a coefficient of determination of 0.013689 which means that $1.37 \%$ of the variability of the professional development of student teachers is explained by ACL. In general, the results of the survey reveal that all the items on the 
questionnaire (cooperative planning among peers; interactive planning with students; active participation; peer tutoring and mutual understanding in an online environment) categorised under ACL were very important to the respondents considering the slight differences in the means and standard deviations. The finding is in line with the socioconstructivists' views on learning. After behaviourism and the cognitive views on learning, came the constructivists. The constructivists, specifically the views of socio-constructivists on learning, have influenced the development of ACL. According to Piskurich (2004:161), ACL includes "e-mail (for question and answer or comments), threaded discussions, and reviews of notes, assignments, and feedback". There is a lot of sharing of ideas between teacher and students as well as between students and students.

The forth research hypothesis (RH4) asserts that internet-based problem- solving (IBPS) has a significant influence on the professional development of student teachers. The findings of the correlation between IBPS and the professional development of student teachers show the following: $r(794)=0.296,(p<0.001)$. From this result, inference was made that IBPS has a significant influence on the professional development of student teachers. The test value gave a coefficient of determination of 0.0876 which means that $8.76 \%$ of the variability of the professional development of student teachers is explained by IBPS. Generally, findings reveal that all the items on the questionnaire (open-ended problems, lifelong learning, mini-group projects, large-group projects and individual assignments) categorised under IBPS were very important to the respondents considering the slight differences in the means and standard deviations. Thus, the internet supports the problem-solving processes of student teachers; and provide them with the opportunity to solve open-ended problems - problems which do not have a closed defined answer among others. Garrison and Anderson (2003:4) maintain that institutions of higher education have gradually started to appreciate the fact that the content of an educational experience will not define quality learning, but that the context; the way in which teachers design the experience and the interactions that drive the learning transaction will ultimately distinguish each institution. It is worthy to note that activity theory has influenced the development of IBPS. Gifford and Enyedy (1999:189) argue that activity-centred design (ACD) is a model or design for computer-supported collaborative learning environments based on the assumptions that: activity is mediated by cultural tools, activity must be conceptualised on a number of interdependent levels, and that conceptual understanding is first established socially. In this light, Gifford and Enyedy (1999:189) view learning as a complex process in which an individual's cognition is defined by his or her relation to the material setting and the forms of social participation encouraged by these settings.

The fifth research hypothesis (RH5) asserts that online content representation (OCR) has a significant influence on the professional development of student teachers. The results of the correlation between OCR and the professional development of student teachers reveal the following: $r(794)=0.180$, $(p<0.001)$. From this finding, inference as made that OCR has a significant influence on the professional development of student teachers. The test value gave a coefficient of determination of 0.0324 which means that $3.24 \%$ of the variability of the professional development of student teachers is explained by OCR. Furthermore, when the responses of the student teachers on the questionnaires in relation to OCR were scored and categorised, it was noticed that all the items (text presentation; graphical representation; video representation; pictorial presentation and audio presentation) were very important to the respondents in enhancing learning and also user-friendly considering the slight differences in the means and standard deviations. In conclusion, the use of OCR has a significant influence on the professional development of student teachers. As a matter of fact, the finding is in line with previous research carried out by David Jonassen on cognitive tools. According to Jonassen (2003:362), the key to problem-solving is adequately representing the problem to be solved. He further explains that problem-solving is at the heart of practice in everyday, professional contexts. Jonassen (2003:364) concludes that problem representation is the key to problem-solving.

The sixth research hypothesis (RH6) claims that online learning environment (OLE) has a significant influence on the professional development of student teachers. The findings of the correlation between OLE and the professional development of student teachers reveal the following: $r(794)=0.120$, $(p<0.001)$. From this result, a conclusion was drawn that OLE has a significant influence on the professional development of student teachers. The test value gave a coefficient of determination of 0.0144 which means that $1.44 \%$ of the variability of the professional development of student teachers is explained by OLE. The result is consistent with previous research by the behaviourists, constructivists and the cultural theorist whose research indicates that the use of technology in a defined environment or context facilitates the acquisition of competences. The finding also shows that all the items (accessibility; flexibility; distance learning; and maximum storage features of the internet) categorised under OLE were very important to the respondents given the slight differences in the means and standard deviations. OLE enables available tools to support not only the relationship of the student teacher with the knowledge to be learnt (learning object), but also all the relationships that are established between participants during a teaching and learning activity. OLE supports the 
evolution of students' and teachers' needs during the activities in which they are engaged in any learning domain.

\subsection{Stepwise Multiple Regression Analysis}

The table that follows presents the parameters of the model for Forced Entry Multiple Regression Analysis. From the results, we noticed that two parameters (computer-based direct instruction and internet-based problem-solving) are significant showing that they were better predictors of the professional development of student teachers. At this level we felt the need to conduct a stepwise multiple regression analysis to find out if other models could emerge.

Table 1: Table of Coefficients

\begin{tabular}{|l|c|c|c|c|c|c|c|}
\hline \multirow{2}{*}{ Model } & \multicolumn{2}{c|}{$\begin{array}{c}\text { Unstandardised } \\
\text { Coefficients }\end{array}$} & $\begin{array}{c}\text { Standardised } \\
\text { Coefficients }\end{array}$ & \multirow{2}{*}{$\mathrm{T}$} & \multirow{2}{*}{ Sig. } & \multicolumn{2}{c|}{$\begin{array}{c}\text { Colinearity } \\
\text { Statistics }\end{array}$} \\
\cline { 2 - 3 } & $\mathrm{B}$ & Std. Error & Beta & & & Tolerance & VIF \\
\hline (Constant) & 75.172 & 5.354 & & 14.040 & 0.000 & & \\
computer-based direct instruction & 0.827 & 0.196 & 0.162 & 4.219 & 0.000 & 0.761 & 1.314 \\
asynchronous experiential learning & -0.381 & 0.222 & -0.064 & -1.718 & 0.086 & 0.794 & 1.259 \\
1 asynchronous collaborative learning & -0.056 & 0.241 & -0.009 & -0.232 & 0.817 & 0.742 & 1.348 \\
internet-based problem-solving & 1.624 & 0.242 & 0.258 & 6.701 & 0.000 & 0.757 & 1.321 \\
online content representation & 0.338 & 0.238 & 0.054 & 1.420 & 0.156 & 0.786 & 1.272 \\
online learning environment & 0.006 & 0.260 & 0.001 & 0.023 & 0.982 & 0.816 & 1.226 \\
\hline
\end{tabular}

a. Dependent Variable: Professional development of student-teachers

Table 2: Descriptive Statistics of models in relation to Mean and Standard Deviation

\begin{tabular}{|l|c|c|c|}
\hline & Mean & Std. Deviation & N \\
\hline Professional development of student-teachers & 121.4284 & 15.47686 & 796 \\
computer-based direct instruction & 18.3204 & 3.02636 & 796 \\
asynchronous experiential learning & 14.5704 & 2.62093 & 796 \\
asynchronous collaborative learning & 14.9636 & 2.49426 & 796 \\
internet-based problem-solving & 19.6558 & 2.45454 & 796 \\
online content representation & 16.2399 & 2.44928 & 796 \\
online learning environment & 12.9020 & 2.20701 & 796 \\
\hline
\end{tabular}

The correlations matrix that follows shows that all the predictors (online learning environment; asynchronous experiential learning; online content representation; asynchronous collaborative learning; computer-based direct instruction; and internet-based problem-solving) correlate well with the outcome variable (professional development of student teachers). The bivariate correlations among variables are all significant. Thus, there is no fear of multicolinearity between variables, since none of the correlations is above 0.9 .

Table 3: Table of Correlations Matrix

\begin{tabular}{|c|c|c|c|c|c|c|c|c|}
\hline & & 1 & 2 & 3 & 4 & 5 & 6 & 7 \\
\hline 1 & computer-based direct instruction & 1 & & & & & & \\
\hline 2 & asynchronous experiential learning & $0.305^{* *}$ & 1 & & & & & \\
\hline 3 & asynchronous collaborative learning & $0.317^{* k}$ & $0.367^{\text {*k }}$ & 1 & & & & \\
\hline 4 & internet-based problem-solving & $0.283^{* k}$ & $0.318^{* *}$ & $0.353^{\text {*t }}$ & 1 & & & \\
\hline 5 & online content representation & $0.355^{* *}$ & $0.121^{\text {*t }}$ & $0.137^{\text {tk }}$ & $0.303^{\text {*t }}$ & 1 & & \\
\hline 6 & Online learning environment & $0.237^{* *}$ & $0.111^{* *}$ & $0.294^{* k}$ & $0.286^{* *}$ & $0.316^{* k}$ & 1 & \\
\hline 7 & professional development of student teachers & $0.231^{* *}$ & $0.070^{*}$ & $0.117^{\text {*t }}$ & $0.296^{\text {*t }}$ & $0.180^{* \text { *t }}$ & $0.120^{* *}$ & 1 \\
\hline
\end{tabular}


The table below presents the predictor variables that were entered into the stepwise multiple regression analysis. The table shows that all the variables were entered. As a result, two models were extracted to predict the professional development of student teachers.

Table 4: Table of Variables Entered/Removed ${ }^{a}$

\begin{tabular}{|c|c|c|c|}
\hline Model & Variables Entered & $\begin{array}{l}\text { Variables } \\
\text { Removed }\end{array}$ & Method \\
\hline $\begin{array}{l}1 \\
2\end{array}$ & $\begin{array}{l}\text { internet-based problem- } \\
\text { solving } \\
\text { computer-based direct } \\
\text { instruction }\end{array}$ & $\cdot$ & $\begin{array}{l}\text { Stepwise (Criteria: Probability-of-F-to-enter <=0.050, } \\
\text { Probability-of-F-to-remove >=0.100). } \\
\text { Stepwise (Criteria: Probability-of-F-to-enter <=0 .050, } \\
\text { Probability-of-F-to-remove }>=0.100 \text { ). }\end{array}$ \\
\hline
\end{tabular}

a. Dependent Variable: Professional development of student-teachers

The summary table below shows two models. In the first model, Pearson correlation $\mathrm{R}=0.296$ and $\mathrm{R} 2=0.088$. This implies that the predictor variable (internet-based problem-solving) accounts for $8.80 \%$ of the variability of professional development of student teachers. Also in the second model, Pearson correlation $\mathrm{R}=0.334$ and $\mathrm{R} 2=0.111$. This implies that the predictor variable (internet-based problem-solving, computer-based direct instruction) accounts for $11.10 \%$ of the variability of professional development of student teachers. Thus, the second model is a better predictor of the professional development of student teachers

Table 5: Table of Model Summaryc

\begin{tabular}{|c|c|c|c|c|c|c|c|c|c|c|}
\hline \multirow{2}{*}{ Model } & \multirow{2}{*}{$\mathrm{R}$} & \multirow{2}{*}{$\begin{array}{c}\mathrm{R} \\
\text { Square }\end{array}$} & \multirow{2}{*}{$\begin{array}{c}\text { Adjusted } \mathrm{R} \\
\text { Square }\end{array}$} & \multirow{2}{*}{$\begin{array}{c}\text { Std. Error of the } \\
\text { Estimate }\end{array}$} & $\begin{array}{c}\text { R Square } \\
\text { Change }\end{array}$ & $\begin{array}{c}\mathrm{F} \\
\text { Change }\end{array}$ & df1 & df2 & $\begin{array}{c}\text { Sig. F } \\
\text { Change }\end{array}$ & Durbin- \\
Watson
\end{tabular}

a. Predictors: (Constant), Internet-based problem-solving

b. Predictors: (Constant), Internet-based problem-solving, Computer-based direct instruction

c. Dependent Variable: Professional development of student-teachers

The ANOVA table below shows two values of F-ratio. In the first model, results displayed in the ANOVA table show that F-ratio is highly significant; $F(1,794)=76.321, p<0.001$. This result reveals that there is less than a $0.1 \%$ chance that an F-ratio of this magnitude would occur by chance alone. Therefore, we can conclude that our regression model results are significantly a better prediction of the professional development of student teachers. Also, the second model shows that F-ratio is highly significant; $F(2,793)=49.676, p<0.001$. This result reveals that there is less than a $0.1 \%$ chance that an F-ratio this large would occur by chance alone. Therefore, we can conclude that our regression model results are significantly a better prediction of the professional development of student teachers.

Table 6: Regression Model ANOVAa for professional development of student-teachers

\begin{tabular}{|c|c|c|c|c|c|}
\hline Model & Sum of Squares & df & Mean Square & $F$ & Sig. \\
\hline Regression & 16699.232 & 1 & 16699.232 & 76.321 & $0.000^{b}$ \\
\hline 1 Residual & 173729.686 & 794 & 218.803 & & \\
\hline Total & 190428.918 & 795 & & & \\
\hline Regression & 21201.872 & 2 & 10600.936 & 49.676 & $0.000^{c}$ \\
\hline 2 Residual & 169227.046 & 793 & 213.401 & & \\
\hline Total & 190428.918 & 795 & & & \\
\hline
\end{tabular}

a. Dependent Variable: Professional development of student-teachers

b. Predictors: (Constant), Internet-based problem-solving

c. Predictors: (Constant), Internet-based problem-solving, Computer-based direct instruction 
Now we can consider the parameters of our model. The table below presents b-value estimates. These values indicate the individual contribution of each predictor to the model. We can now consider the parameters of our model. The table gives the b-value estimates. These values indicate the individual contribution of each predictor to the model. It would appear that internet-based problem-solving $(\mathrm{t}(794)=7.183, \mathrm{p}<0.001)$, computer-based direct instruction $(\mathrm{t}(794)=$ $4.593, p<0.001)$ are all significant predictors of the professional development of student teachers in Cameroon.

Table 7: Table of Model Coefficients ${ }^{\mathrm{a}}$

\begin{tabular}{|c|c|c|c|c|c|c|c|}
\hline \multirow{2}{*}{ Model } & \multicolumn{2}{|c|}{ Unstandardised Coefficients } & \multirow{2}{*}{\begin{tabular}{|c|} 
Standardised Coefficients \\
Beta \\
\end{tabular}} & \multirow{2}{*}{$\mathrm{T}$} & \multirow{2}{*}{ Sig. } & \multicolumn{2}{|c|}{ Colinearity Statistics } \\
\hline & B & Std. Error & & & & Tolerance & VIF \\
\hline (Constant) & 84.727 & 4.234 & & 20.01 & 0.000 & & \\
\hline $\begin{array}{l}\text { internet-based problem- solving } \\
\text { (Constant) }\end{array}$ & $\begin{array}{c}1.867 \\
75.334\end{array}$ & $\begin{array}{l}0.214 \\
4.654\end{array}$ & 0.296 & $\begin{array}{l}8.736 \\
16.18\end{array}$ & 0.000 & 1.000 & 1.000 \\
\hline 2 internet-based problem-solving & 1.581 & 0.220 & 0.251 & 7.183 & 0.000 & 0.920 & 1.087 \\
\hline computer-based direct instruction & 0.820 & 0.179 & 0.160 & 4.593 & 0.000 & 0.920 & 1.087 \\
\hline
\end{tabular}

a. Dependent Variable: Professional development of student-teachers

The magnitude of the t-statistics, suggests that internet-based problem-solving and computer-based direct instruction have an unprecedented role in fostering the professional development of student teachers. Therefore, by replacing betavalues into an equation we would, be able to define our regression model as follows:

\section{professional development $=(1.581)$ internet-based problem-solving $+(0.820)$ computer-based direct instruction + 75.334}

The standardised beta value for internet-based problem- solving indicates that this variable has a higher degree of importance in the model. The following table summarises the results of our regression model.

Table 8: Summary of Stepwise Multiple Regression Analysis

\begin{tabular}{|c|c|c|c|}
\hline & $B$ & SEB & B \\
\hline \multicolumn{4}{|l|}{ Step 1} \\
\hline Constant & $84.727^{\star \star \star}$ & $4.234^{\star \star \star}$ & \\
\hline internet-based problem -solving & $1.867^{\star \star \star}$ & $0.214^{\star \star \star}$ & $0.296^{\star \star \star}$ \\
\hline \multicolumn{4}{|l|}{ Step 2} \\
\hline (Constant) & $75.334^{\star \star \star}$ & $4.654^{\star \star \star}$ & \\
\hline internet-based problem-solving & $1.581^{\star \star \star}$ & 0.220 *** & $0.251^{\star \star *}$ \\
\hline computer-based direct instruction & $0.820^{\star \star \star}$ & 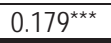 & $0.160^{\star \star \star}$ \\
\hline
\end{tabular}

Note : $R^{2}=.088$ for Step $1, \Delta R^{2}=.024$ for Step $2\left({ }^{\star \star \star}=p<.001\right)$,

$$
Y=\beta_{0}+\beta_{1} X_{1}+\beta_{2} X_{2}+\ldots+\beta_{K} X_{K}+\varepsilon
$$

Finally, results of our Stepwise Multiple Regression Analysis reveal that two models (internet-based problem-solving and computer-based direct instruction are the best predictors of professional development of student teachers in Cameroon as could be seen in the Stepwise Multiple Regression Analysis above

\section{Concluding Remarks}

Finally, results have proven that the use of e-learning has a significant influence on the professional development of student teachers. Findings of the Stepwise Multiple Regression analysis suggest that internet-based problem-solving and computer-based direct instruction have an unprecedented role in fostering the professional development of student teachers in Cameroon. These results have revealed that there is the emerging presence of alternative conceptions or models of e-learning challenging institutions in Cameroon to look beyond the limitations of this strategy. These alternative perspectives (models) offer fresh insights and encourage greater research in the area of e-learning in Cameroon and 
Africa as a whole. Consequently, teachers must learn to use strategies and models that are multidimensional and encompassing in order to solve existing and future educational challenges. Furthermore, the initial professional development of prospective teachers must be considered as a priority. Teacher education in e-learning must, thus, be viewed as fundamental to any meaningful development in developing countries.

\section{References}

Brown, S. J. (2002). The social life of learning: how can continuing education be reconfigured in the future? Continuing Higher Education Review. 66:50-69.

COL. (2006). Learning and living with technology: the commonwealth of learning and the millennium development goals. COL

COL. (2006). Commonwealth of learning development plan 2006-2009. COL.

Crook, C. (2001). The social character of knowing and learning: implications of cultural psychology for educational technology. Journal of Information Technology for Teacher Education 10(1 \& 2), 19-36.

Falola, T. (2000). African cultures and societies before 1885. USA: Carolina Academic Press.

Fonkeng, E.G. (2007). The history of education in Cameroon, 1844-2004. New York: Edwin Mecler Press.

Freire, P. (1984). Pedagogy of the oppressed. New York: Continuum.

Gifford, R. B. \& Enyedy, D. N. (1999). Activity centered designs: towards a theoretic framework for CSCL. Computer Support for Collaborative Learning 189-197.

Jonassen, D. (2003). Using cognitive tools to represent problems. Journal of Research on Technology in Education 35(3), 362-37.

Moore, A. (2000). Teaching and learning: pedagogy, curriculum and culture. London: Routledge and Palmer.

Naidu, S. (2003). ELearning: a guide book of principles, procedures and practice. CEMCA.

Perkinson, R. (2005). Beyond secondary education: the promise of ICT for higher education and lifelong learning, In. E-Development: From Excitement to Effectiveness, edited by The World Bank. 101-125. Washington.

Santrock, J. W (2004). Educational psychology. (2nd edition), New York: McGraw-Hill..

Tamanji, C. A (2011). Three instances of Western colonial governments and Christian missions in Cameroon education: 1884-1961. Chicago: Loyola University.

Tambo, I. L. (2000). Strategic concerns in curriculum development for Cameroon schools. In Educational Development in Cameroon 1961-1999: Issues and Perspectives, edited by T.M. Ndongko and I. L. Tambo Nkemnji Global Tech:153-165.

$\mathrm{Tu}, \mathrm{C} . \mathrm{H}$. (2000). On-line learning migration: from social learning theory to social presence theory in a CMC environment. Journal of Network and Computer Application 23:27-37. 